\title{
Covert Reorienting and Inhibition of Return: An Event-Related fMRI Study
}

\author{
Jöran Lepsien ${ }^{1}$ and Stefan Pollmann ${ }^{2}$
}

\begin{abstract}
Using event-related fMRI, we analyzed the functional neuroanatomy of covert reorienting and inhibition of return (IOR). Covert reorienting to a target appearing within 250 msec after an invalid contralateral location cue elicited increased activation in the left fronto-polar cortex (LFPC), right anterior and left posterior middle frontal gyrus, and right cerebellum, areas that have previously been associated with attentional processes, specifically attentional change. In contrast, IOR, which leads to prolonged response times to targets that appear at the cued location at a stimulus-
\end{abstract}

\section{INTRODUCTION}

When visual attention is reflexively directed to a given spatial location, a typical pattern of reaction times (RT) is observed: When the cue validly predicts the target position, target detection is facilitated within a stimulusonset-asynchrony (SOA) up to $250 \mathrm{msec}$ compared to target detection at an uncued location (invalid cueing). This facilitation is automatic, it occurs even when the cue validity is at chance level. In contrast, when the SOA between cue and target exceeds $250 \mathrm{msec}$, the detection of the target becomes slower at the cued relative to the uncued location. This phenomenon is called inhibition of return (IOR, Posner \& Cohen, 1984).

The goal of this study was twofold: (1) To analyze which brain areas support the spatial bias underlying IOR, and (2) to analyze whether the same, or different, areas support covert reorienting, which becomes necessary when the target is presented at an unattended location.

Covert reorienting describes those processes that counteract attentional capture by an invalid cue at an SOA $<250$ msec. Behaviorally, these processes are represented by the increased response times for invalidly cued targets at short SOA. The facilitatory effect of valid noninformative peripheral cues is commonly interpreted as a stimulus-induced allocation of attentional

\footnotetext{
${ }^{1}$ Max-Planck-Institute of Cognitive Neuroscience, ${ }^{2}$ University of Leipzig
}

onset-asynchrony (SOA) $>250 \mathrm{msec}$, was accompanied by increased activation in brain areas involved in oculomotor programming, such as the right medial frontal gyrus (supplementary eye field; SEF) and the right inferior precentral sulcus (frontal eye field; FEF), supporting the oculomotor bias theory of IOR. Pre-SEF and pre-FEF areas were involved both in covert reorienting and IOR. The supramarginal gyri were bilaterally involved in IOR, with the right supramarginal gyrus additionally involved in covert reorienting.

resources to those brain areas that process stimuli at the cued location.

The second phenomenon to be explained is IOR. Initial reorienting to a target at an uncued location requires counteracting a still active attentional capture by the cued location, while IOR is observed after this attentional capture has declined. IOR may differ from initial reorienting in the nature of the underlying process. Behavioral evidence suggests that IOR is not a purely attentional phenomenon, but that it involves motor processes as well. Initially, IOR was assumed to indicate a bias against returning attention to previously examined locations, although it was clear from the initial experiments that the inhibition observed at cued locations when target presentation was delayed was different in many respects from initial facilitation (Posner \& Cohen, 1984). Posner and Cohen suggested that "IOR builds up over the same time interval as initial facilitation but is simply masked by larger facilitation." While Posner and Cohen discussed facilitation and IOR as caused by different attentional processes, subsequently, Tassinari et al. (1987, 1989) proposed IOR to be a consequence of maintaining fixation during the experiments, so saccades initiated by cues have to be suppressed, biasing the motor system against responding in the cued direction. In the view of Taylor \& Klein (1998) IOR reflects an inhibition for making motor responses to a previously cued location, that is, IOR is represented in a spatial motor map that directs attention, and it is generated by the activation of an oculomotor program to fixate the cue. 
Subsequent studies have provided evidence both for the attentional as well as for the motor account (Collie, Maruff, Yucel, Danckert, \& Currie, 2000; Kingstone \& Pratt, 1999; Taylor \& Klein, 1998, 2000; Reuter-Lorentz, Jha, \& Rosenquist, 1996), suggesting that both mechanisms contribute to IOR.

In essence, it is still an unresolved question whether initial facilitation at the cued location and IOR are caused by separate facilitatory and inhibitory processes with different time-courses, or by a unitary biphasic attentional process that initially facilitates processing at the cued location and subsequently "shifts" to inhibit processing at previously attended locations.

\section{Predictions for Brain Activation}

Whatever the nature of the process underlying IOR may be, it can be predicted that the associated brain activation should increase with increasing SOA. This can be illustrated if we look at the predictions made by the motor bias explanation of IOR: An oculomotor bias underlying IOR would be caused by the fact that subjects have to keep fixation in the presence of a peripheral cue, leading to a bias against the cued hemifield. Note that although this bias will lead to reduced RT to targets at the uncued, and prolonged RTs at the cued hemifield, the bias itself is present in both kinds of trials and should thus elicit the same amount of activation in brain areas supporting this bias in valid as well as invalid trials.

The exact time-course of such a motor bias is as yet unknown, the consistent finding of initial facilitation and subsequent IOR at validly cued locations can be explained in two ways: (i) by a combination of an initial short-lived facilitatory attentional orienting process and a subsequent inhibitory motor bias, or (ii) by superposition of initial short-lived attentional orienting and a concurrent inhibitory motor bias of longer duration. In the second explanation, the initial facilitation outweighs the inhibition, which becomes visible only after the facilitatory process declines (Klein, 2000; see Figure 1 for a schematic outline of the hypothetical time-courses of initial facilitation and IOR). For the present study, both explanations imply that the activation associated with IOR should increase at longer SOA, whereas the initial attentional capture should be identical in both, generating the same amount of activation. Thus, the motor bias theory of IOR predicts a main effect of SOA in the absence of an interaction of SOA $\times$ Validity.

Of course, the same activation pattern would be expected if IOR was caused by an inhibitory process of a different nature, such as an inhibitory attentional process.

A very different pattern of activations can be predicted for brain areas that support covert reorienting. At a short SOA, covert reorienting occurs against stimulus-driven attentional capture by the cue, and, consequently, is expected to be present in invalid cue trials, namely, when the target appears at an uncued location. At longer SOA, when IOR is observed, the predictions are less straightforward, based on the uncertainty whether IOR is caused by a reallocation of attentional resources, or by a motor bias. In any case, at long SOA, we observe longer detection times for targets at the cued location, and if the same brain areas are involved in counteracting IOR that are active in counteracting attentional capture at short SOA, then we would expect an interaction of cue validity and SOA in these areas.

\section{Functional Neuroanatomic Hypotheses}

fMRI studies of the visual cortex have demonstrated that allocation of attention to a particular location leads to increased activation in those parts of retinotopic visual areas that represent this location, as well as decreased activation levels in the remaining parts (Brefczynski \& DeYoe, 1999; Tootell et al., 1998). Thus, when a target appears within $250 \mathrm{msec}$ at a different location than the cued one, the subject has to counteract a misallocation of attentional resources that has its physiological equivalent in altered activation levels in visual cortex.

It is not unlikely that covert reorienting of attention, which becomes necessary when the target appears outside the cued location, is supported by a devoted brain area. A potential candidate is the left fronto-polar cortex
Figure 1. Illustration of the hypothetical time-courses of initial facilitation and IOR: The different lines indicate the onset and duration of facilitation, and the relative onset and development of IOR. IOR may be observed with a delay after initial facilitation either because its onset is delayed, or because it starts with cue onset, but is initially overridden by the facilitation effect. The arrows in the bottom row indicate the positions of cue and targets in time.

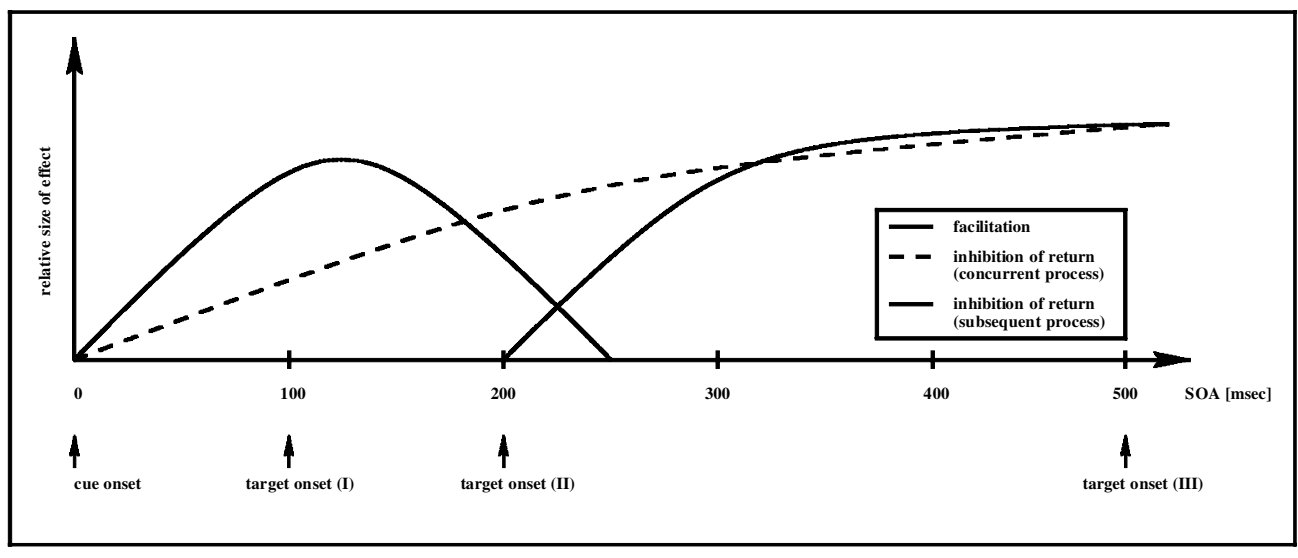


Figure 2. Illustration of the trial structure: The subjects had to make a speeded simple response to the appearance of the target. All cues were totally uninformative to the target location. SOA $=$ stimulus onset asynchrony; ITI $=$ intertrial interval.

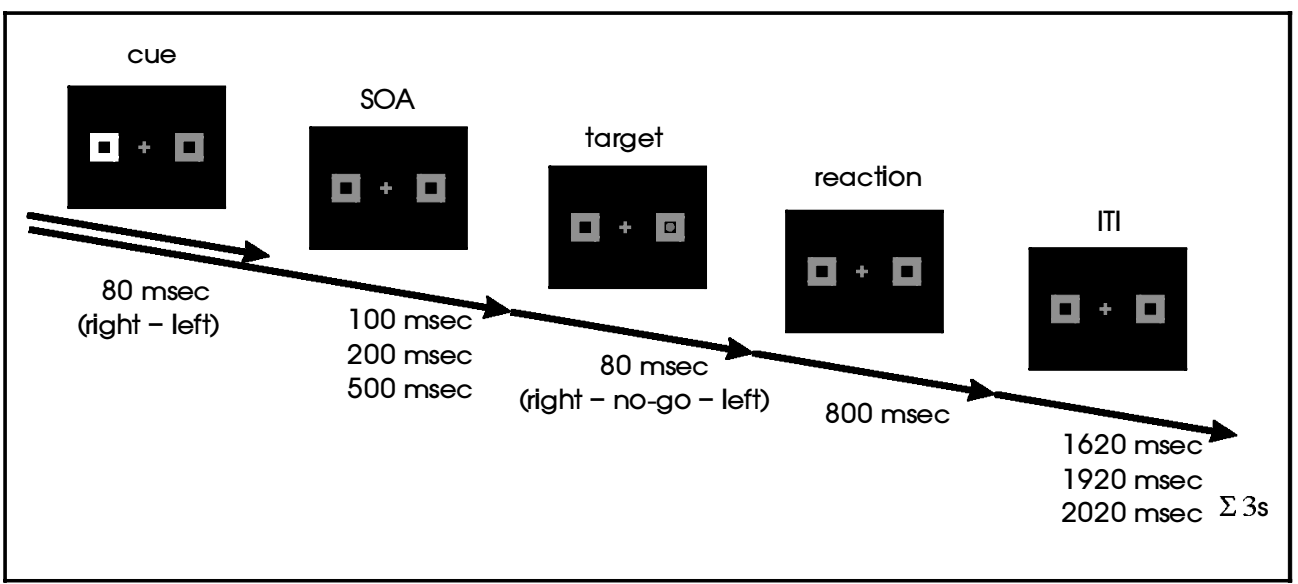

(LFPC). Recently, we found activation in this area to accompany attentional switching between color and motion (Pollmann, Weidner, Müller, \& von Cramon, 2000). Apart from the attentional selection domain (dimensions vs. locations), this study and the present study had several aspects in common. Attention was reflexively captured by salient stimuli (pop-out stimuli in the previous study, luminance onsets in the current study) and had to be reallocated when an unexpected target occurred (a singleton defined in a new dimension, respectively, a target at an uncued location). Thus, if the LFPC supports the reallocation of attentional resources not only between visual dimensions but also between locations, it should be active when subjects reorient to a target at an uncued location at short SOA, when attention is still captured by the cued location. At long SOA, fronto-polar activation would be expected insofar as attentional reorienting is necessary.

In contrast, we expected motor areas of the brain, and specifically areas subserving oculomotor responses, to be associated with IOR. Specifically, the superior colliculi (SC) have been implied in the generation of IOR in previous studies (Sapir, Soroker, Berger, \& Henik, 1999; Posner, Rafal, Choate, \& Vaughan, 1985).

To test these hypotheses, we applied an exogenous spatial cueing paradigm for covert shifts of attention (Posner \& Cohen, 1984). Throughout our experiment, a peripheral luminance increase highlighted one of two possible target locations. This cue was followed by the target at a stimulus onset asynchrony (SOA) of 100, 200 , or $500 \mathrm{msec}$, in random order. Subjects were instructed to press a button when they had detected the presence of the target. Details of the experimental method are described in the Methods section and in Figure 2.

\section{RESULTS}

\section{Behavioral Performance}

The error rates (false alarms and misses) were negligible (1\%) for 17 out of 20 subjects, the remaining subjects made $7.5 \%, 12 \%$, and $18.5 \%$ errors. The latter two were excluded from the study because their high error rates $(>10 \%)$ made the interpretation of their data questionable. We take the low error rates in the remaining subjects as evidence against eye-movements (see Methods for details). All error trials and outliers (defined by RTs shorter than 100 msec or longer than $800 \mathrm{msec}$ ) were removed. Moreover, we discarded all trials immediately following resting baselines. In total this resulted in, on average, an additional loss of $2 \%$ of the data per subject. For all behavioral analyses the significance criterion was set to $\alpha=.05$.

A $3 \times 2$ repeated measures ANOVA of SOA (100, 200, and $500 \mathrm{msec}) \times$ Validity (valid, invalid) was calculated for the group of 18 subjects, revealing a significant main effect for validity $[F(1,17)=16.64, p<.001]$, and for SOA $[F(2,34)=21.78, p<.001]$. Most important, the interaction reached significance $[F(2,34)=17.5, p<$ $.001]$, as expected due to the dependence of facilitation and inhibition from SOA.

In order to obtain a pure measure of the processes of interest, we included only 11 subjects that showed the typical RT pattern as reported in the behavioral literature [see Klein (2000) for a recent review], that is, a facilitation in target detection for valid trials at the $\mathrm{SOA}=100 \mathrm{msec}$ and $\mathrm{IOR}$ at the $\mathrm{SOA}=500 \mathrm{msec}$.

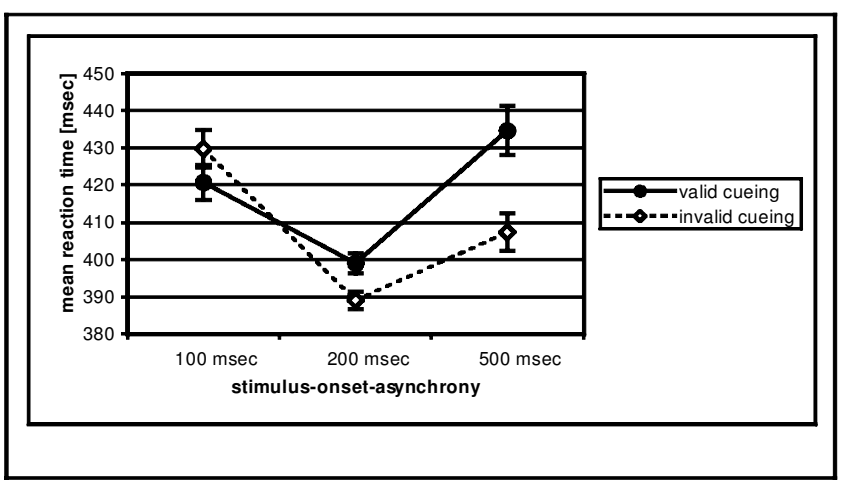

Figure 3. Mean RTs averaged over 11 subjects. The bars indicate the standard errors of mean for within subject-designs (Loftus \& Masson, 1994). 
Again a repeated measures ANOVA was calculated for this subgroup. It revealed significant main effects for SOA $[F(2,20)=13.23, p<.001]$ and validity $[F(1,10)=$ 9.46, $p<.012]$ and a significant interaction of SOA and validity $[F(2,20)=12.2, p<.001]$.

As can be seen in Figure 3, a small inhibitory cueing effect was observed at SOA $=200 \mathrm{msec}$. However, because the RT difference is very small compared to $\mathrm{SOA}=500 \mathrm{msec}$, we used only the SOA $=100 \mathrm{msec}$ and $\mathrm{SOA}=500 \mathrm{msec}$ for the subsequent analyses.

A $2 \times 2$ repeated measures ANOVA of SOA $(100 \mathrm{msec}$, $500 \mathrm{msec}) \times$ Validity (valid, invalid) revealed a significant interaction of SOA and validity $[F(1,10)=21.93, p<$ .001 ], but no significant main effects [SOA: $F(1,10)=$ $0.24, p<.634$; validity: $F(1,10)=3.84, p<.079$ ]. Paired $t$ tests for valid versus invalid cues at SOA $=100 \mathrm{msec}$ and SOA $=500 \mathrm{msec}$, respectively $(t=4.15, p<.002$ and $t=-3.28, p<.008)$, indicated significant facilitation and IOR effects.

\section{fMRI Results}

\section{Covert Reorienting}

To image brain areas enabling target detection against attentional capture, respectively, against IOR, we calculated the interaction of cue Validity $\times$ SOA:

$$
\begin{aligned}
& (\text { invalid } / \mathrm{SOA}=100 \mathrm{msec}-\text { valid } / \mathrm{SOA}=100 \mathrm{msec}) \\
& \quad-(\text { invalid } / \mathrm{SOA}=500 \mathrm{msec}-\text { valid } / \mathrm{SOA}=500 \mathrm{msec})
\end{aligned}
$$

This interaction contrast (Figure 4a) yielded a large activation in the LFPC. Further significant activations were observed in the right anterior middle frontal gyrus, reaching into the inferior frontal sulcus, in the left posterior middle frontal gyrus, next to the inferior precentral sulcus [consistent with the inferior frontal eye fields (FEF), Luna et al., 1998], and right cerebellum. Several activations, although of very small extent, were found in posterior cortices (Table 1A).

To test in which way cue validity and SOA contributed to the interaction, we extracted the signal change (in percent; PSC) for the activated areas (only large activations, Figure 4a) for all experimental conditions.

Repeated measures ANOVAs of SOA (100 msec, 500 msec) $\times$ Validity (valid, invalid) over PSC revealed significant interactions for all regions of interest (ROI) (all $p s \leq .044)$, but no significant main effects for SOA (all $p s \geq .502$ ) and validity (all $p s \geq .619$ ) (Table $4 a$ ).
In all of these areas, the strongest PSC was observed for invalid trials at $\mathrm{SOA}=100 \mathrm{msec}$ and for valid trials at $\mathrm{SOA}=500 \mathrm{msec}$. In addition, as indicated by paired $t$ tests (Table 4a), all areas showed significant differences between valid and invalid trials at $\mathrm{SOA}=100 \mathrm{msec}$, whereas valid and invalid trials at SOA $=500 \mathrm{msec}$ only differed significantly in the right middle frontal gyrus and the right cerebellum.

Because it is uncertain whether the increased detection latencies for invalid/SOA $=100 \mathrm{msec}$ and valid/SOA $=500 \mathrm{msec}$ trials are caused by the same processes, we additionally investigated validity effects at both SOA separately. The contrast (invalid/SOA $=100 \mathrm{msec}-$ $\mathrm{valid} / \mathrm{SOA}=100 \mathrm{msec}$ ) yielded many of the same activations as the interaction contrast (Tables 1a and $4 b)$. Additional activations were observed in the left anterior medial frontal gyrus, right posterior medial frontal gyrus, right anterior cingulate gyrus, and right lingual gyrus. Activations of small extent were observed in the left superior and middle frontal and left posterior cingulate gyri.

Contrasting valid minus invalid trials at $\mathrm{SOA}=500$ msec yielded two activations in the right middle frontal gyrus and left cerebellum, brain areas that also showed a significant interaction of Validity $\times$ SOA.

\section{Inbibition of Return}

In order to localize brain areas associated with IOR, we analyzed the main effect of SOA, that is, (valid/SOA $500 \mathrm{msec}+$ invalid/SOA $500 \mathrm{msec})$ - (valid/SOA 100 msec + invalid/SOA $100 \mathrm{msec}$ ). A significant SOA main effect was observed in the right medial frontal gyrus, at the border of the supplementary eye field (SEF) and pre-SEF, and in the right inferior frontal gyrus, extending into the inferior precentral sulcus, at the approximate location of the inferior FEF, as described by Luna et al. (1998). Additional activations of small extent were observed in the supramarginal gyrus bilaterally, as well as in the right ventrolateral nucleus of the thalamus, and in the left inferior parietal lobule, close to the junction of the intraparietal sulcus and the postcentral sulcus, and left cerebellum (Figure 4b, Table 1b). ROI analyses of PSC in the right medial and inferior frontal gyri and left supramarginal gyrus showed a significant main effect of SOA, but neither significant validity effect nor interaction (Table 4a). A significant interaction in addition to a significant SOA main effect was observed in the right supramarginal gyrus (cf. next paragraph).

\footnotetext{
Figure 4. BOLD signal increases related to (a) covert reorienting (as revealed by interaction of cueing validity and SOA), (b) IOR, and (c) IOR and covert reorienting, mapped on axial slices of subjects' averaged anatomical images. Diagrams report percent signal change for all conditions, the titles indicate anatomic labels and coordinates according to Talairach and Tournoux (1988) for each ROI. Bars indicate the two-sided 95\% confidence intervals, calculated for within-subject designs (Loftus \& Masson, 1994). Asterisks (*) indicate significant differences between the conditions V100 and I100, or V500 and I500, respectively (see Table 4 for details). (V100 = valid cueing at SOA = $100 \mathrm{msec} ; \mathrm{I} 100=$ invalid cueing at $\mathrm{SOA}=100 \mathrm{msec} ; \mathrm{V} 500=$ valid cueing at $\mathrm{SOA}=500 \mathrm{msec} ; \mathrm{I} 500=$ invalid cueing at $\mathrm{SOA}=500 \mathrm{msec}$.).
} 
d) Covert Reorienting [(l100 - V100) - (1500 - V500)]
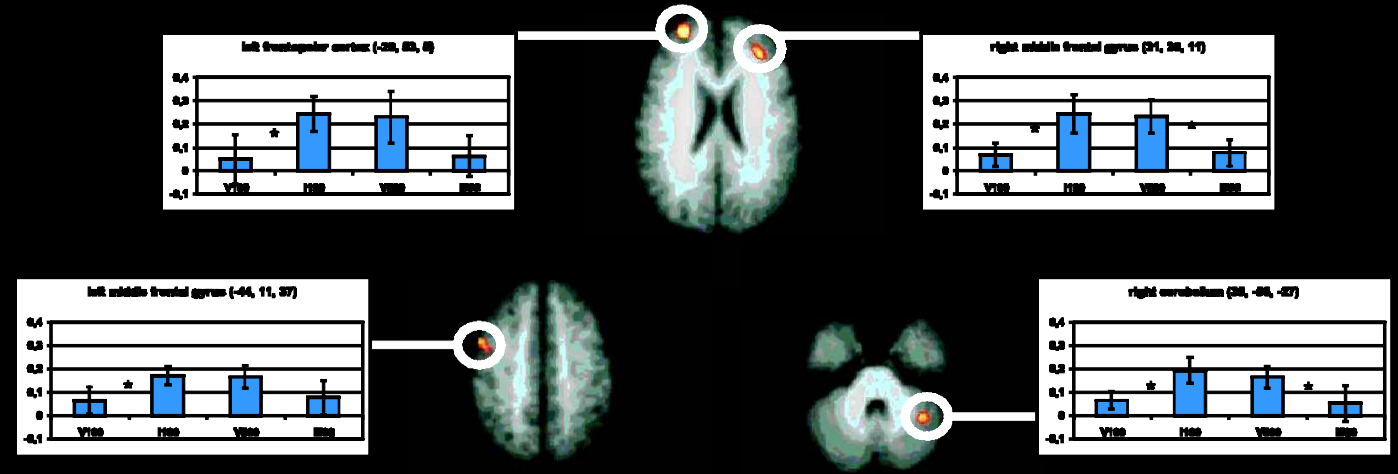

b) Inhibilion of Return $[(N 500+1500)-(N 100+1100)]$

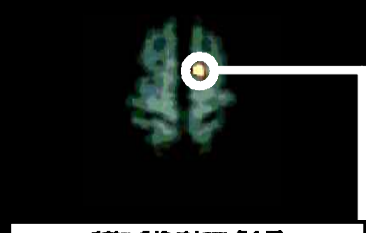

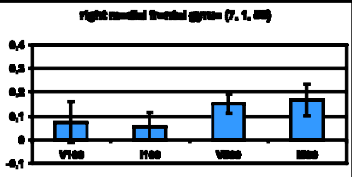



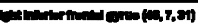

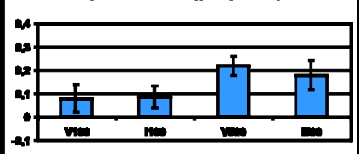

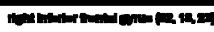

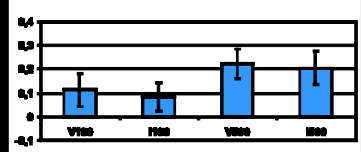

c) Covert Reorienting \& Inhibilion of Rotum [N500 - V100]

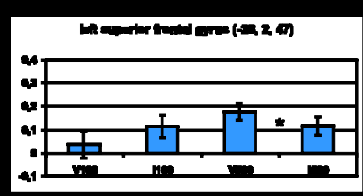

\section{2 - seere}

$=$

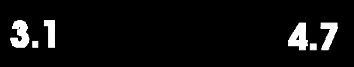

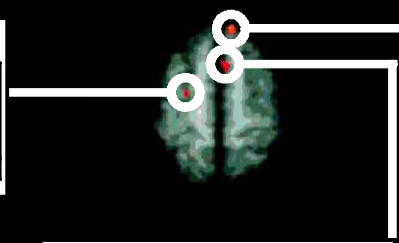

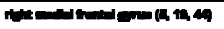

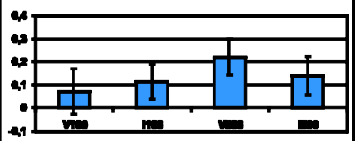

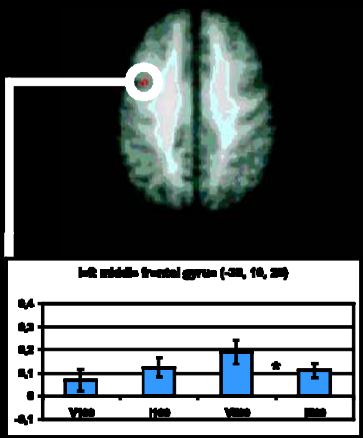

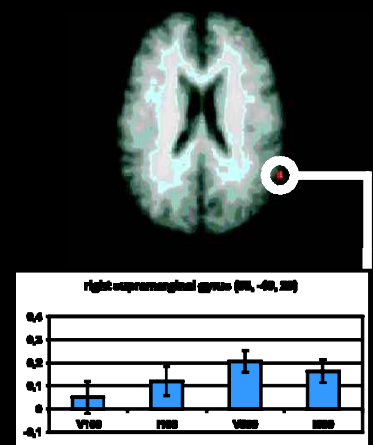

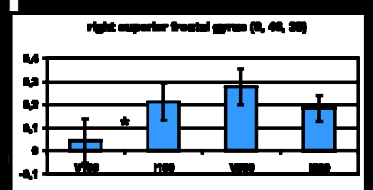

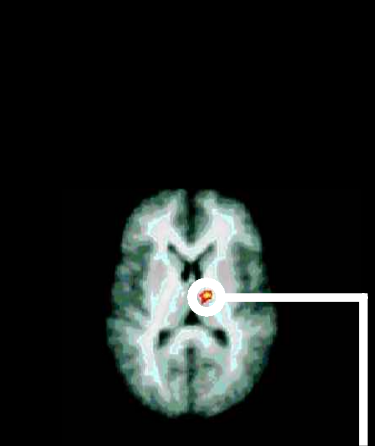

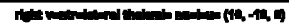

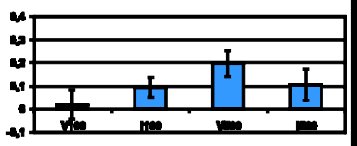




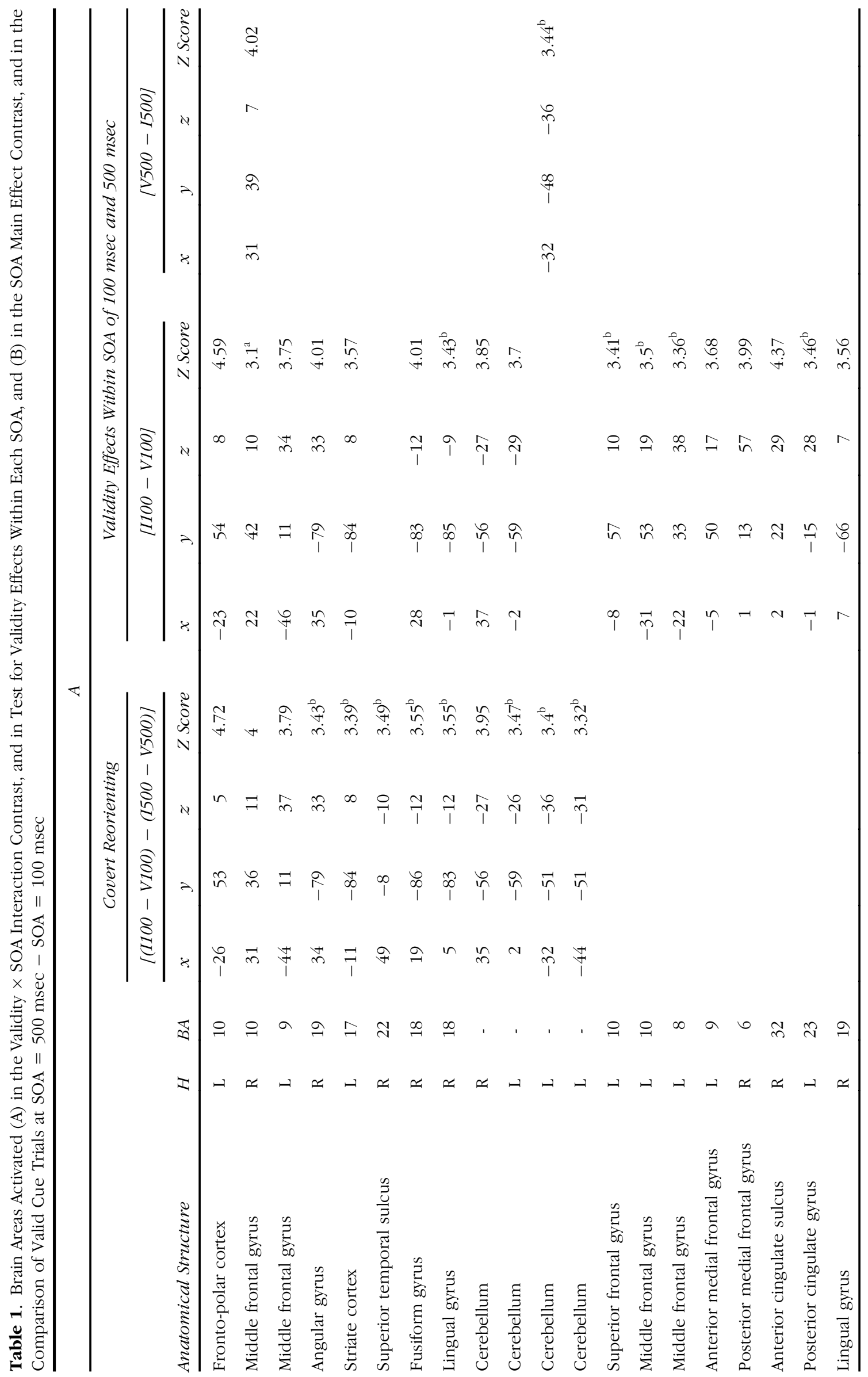




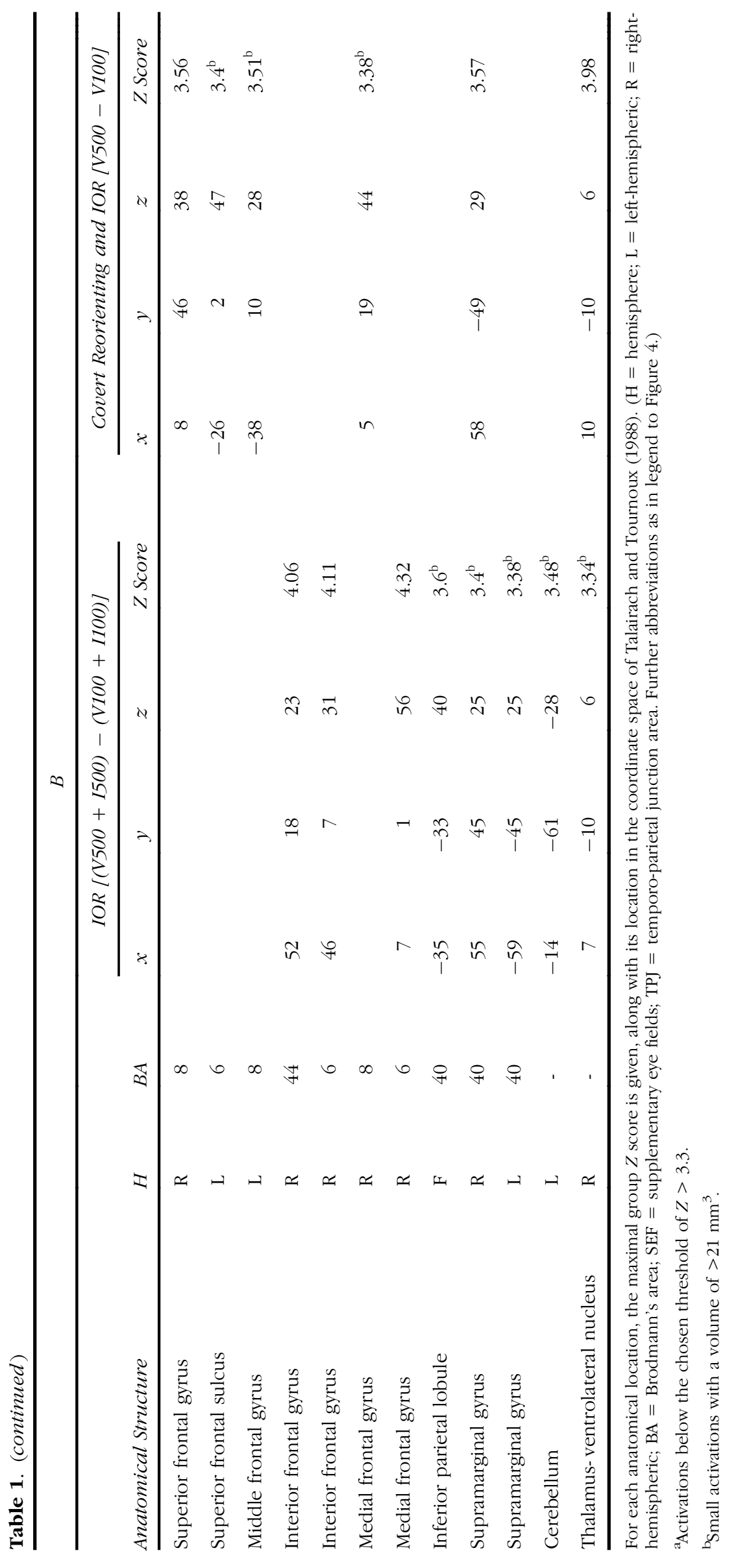




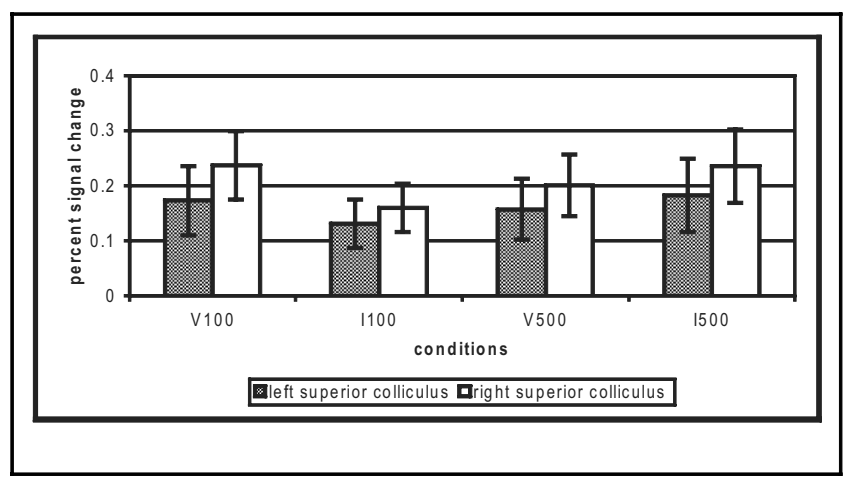

Figure 5. Percent signal change in the SC (mean Talairach coordinates: $x= \pm 5, y=-31, z=0$ ). Abbreviations as in legend to Figure 4 .

\section{Brain Areas Supporting Both Covert Reorienting and $I O R$}

There may be brain areas that are involved both in covert reorienting and IOR. These brain areas may show neither a significant interaction nor a significant main effect of SOA at the significance level of the whole brain analysis, whereas these effects may become apparent at the relaxed significance level adequate for ROI analyses. We searched for these processes in the following way: Both covert reorienting and IOR would predict a significant increase in activation for the valid/SOA $=500$ msec condition over the valid/SOA $=100 \mathrm{msec}$ con- dition. On the one hand, covert reorienting is necessary at $\mathrm{SOA}=500 \mathrm{msec}$, but not at $\mathrm{SOA}=100 \mathrm{msec}$, on the other hand, motor bias-related activation should increase over time.

The comparison of valid SOA $=500 \mathrm{msec}$ trials minus valid $\mathrm{SOA}=100 \mathrm{msec}$ trials (Figure 4c, Table 1b) revealed activation in the anterior right superior frontal gyrus, right medial frontal gyrus (pre-SEF), left posterior superior frontal sulcus (anterior to the junction to the precentral sulcus, pre-FEF), posterior left middle frontal gyrus, bordering precentral sulcus, in the right supramarginal gyrus, and in the ventrolateral nucleus of the thalamus.

Again we extracted amplitude changes for these ROI. The repeated measures ANOVAs of SOA $\times$ validity revealed significant interactions for all ROI (all $p s \leq$ .042 ), and significant main effects for SOA (all $p s \leq .015$ ). No significant main effects for validity were found (all $p s \geq .450$ ).

The PSC to validly cued targets at SOA $=100 \mathrm{msec}$ and validly cued targets at SOA $=500 \mathrm{msec}$ differed significantly from each other (all $p \mathrm{~s} \leq .009$ ). In addition, valid and invalid trials at SOA $=100 \mathrm{msec}$ differed significantly in the right superior frontal gyrus. A significant difference between valid and invalid trials at $\mathrm{SOA}=500 \mathrm{msec}$ was found in the left superior frontal gyrus and the left middle frontal gyrus (see Table 4 a for details).

Table 2. Overview of Covert Attention Imaging Studies

\begin{tabular}{|c|c|c|}
\hline Author & Topic & Technique and Design \\
\hline $\begin{array}{l}\text { Corbetta, Miezin, Shulman, \& } \\
\text { Petersen, 1993; Corbetta, } 1998\end{array}$ & $\begin{array}{l}\text { Endogenous shifting of attention with and } \\
\text { without eye movements }\end{array}$ & PET and fMRI blocked designs \\
\hline Nobre et al., 1997 & $\begin{array}{l}\text { Exogenous covert orienting with } \\
\text { informative cueing }\end{array}$ & PET blocked design \\
\hline Gitelman et al., 1999 & Covert endogenous orienting & fMRI blocked design \\
\hline Kim et al., 1999 & $\begin{array}{l}\text { Endogenous versus exogenous } \\
\text { covert orienting }\end{array}$ & fMRI blocked design \\
\hline Nobre et al., 1999 & Reanalysis of Coull and Nobre (1998) & PET blocked design \\
\hline $\begin{array}{l}\text { Nobre, Gitelman, Dias, } \\
\text { \& Mesulam, } 2000\end{array}$ & $\begin{array}{l}\text { Covert endogenous orienting } \\
\text { versus overt saccade task }\end{array}$ & fMRI blocked design \\
\hline Corbetta et al., 2000 & $\begin{array}{l}\text { Dissociation of voluntary orienting } \\
\text { and target detection }\end{array}$ & fMRI event-related design \\
\hline Hopfinger et al., 2000 & $\begin{array}{l}\text { Endogenously cued spatial attention to } \\
\text { dissociate attentional control and selective } \\
\text { processing of the target }\end{array}$ & fMRI event-related design \\
\hline Perry \& Zeki, 2000 & Covert shifts in spatial attention and saccades & fMRI event-related design \\
\hline
\end{tabular}


Table 3. Brain Areas Activated at $\mathrm{SOA}=100 \mathrm{msec}$ and $\mathrm{SOA}=500 \mathrm{msec}$ as Compared to Fixation

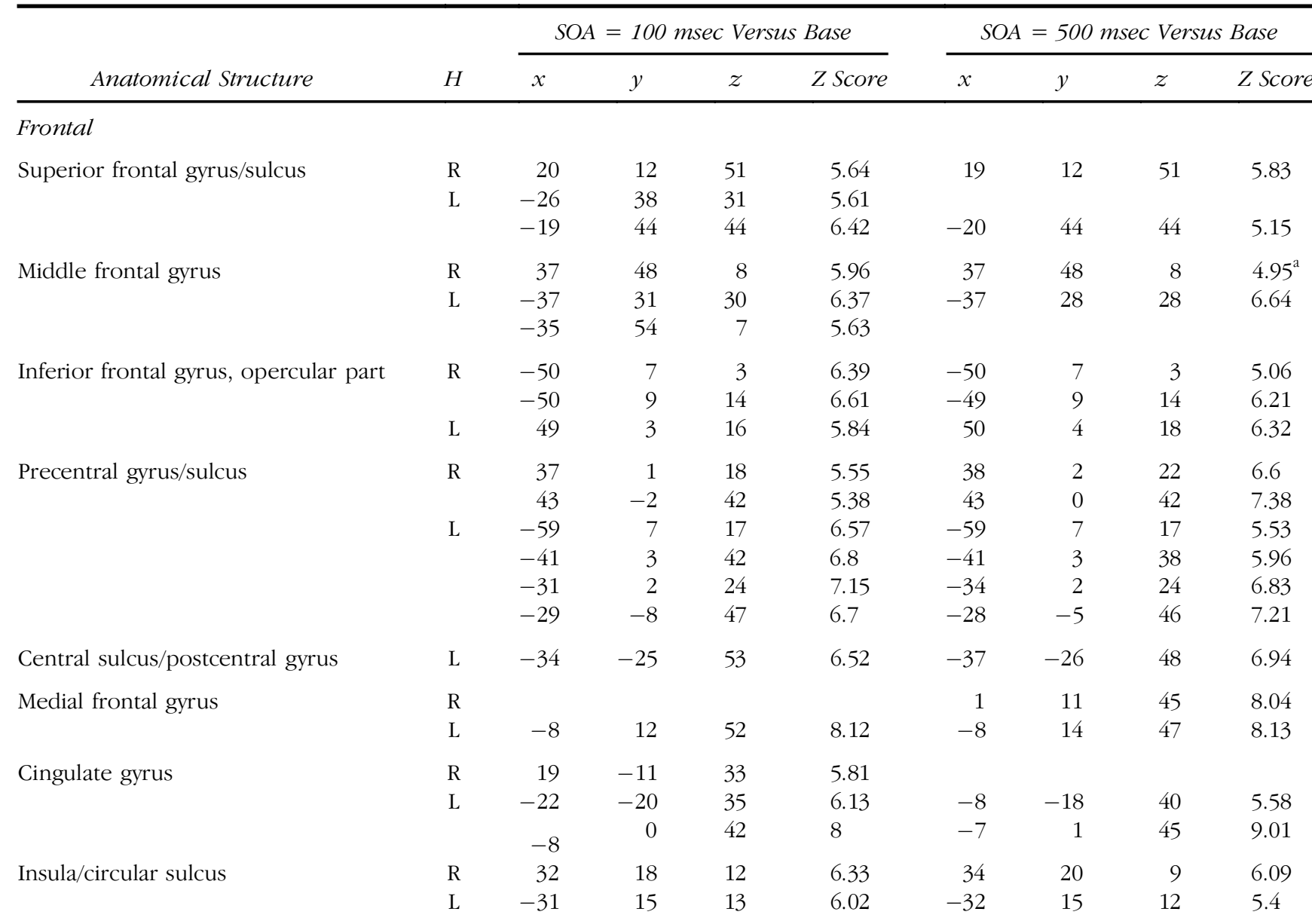

\section{Parietal}

Anterior intraparietal sulcus

R $\quad 28 \quad-52 \quad 42$

$\begin{array}{lrrr}R & 28 & -52 & 42 \\ \mathrm{~L} & -23 & -52 & 42\end{array}$

5.51

7.56

28

$-52$

42

6.52

$\begin{array}{lll}-35 & -51 \quad 55\end{array}$

7.41

-23
-35

$-49$

41

8.53

Posterior intraparietal sulcus

$\begin{array}{llll}\mathrm{R} & 25 & -77 & 21 \\ & 25 & -87 & 20\end{array}$

6.15

$-55$

$-51$

7.41

6.54

$-74$

20

5.67

$\begin{array}{llll}\mathrm{L} & -23 & -88 & 26\end{array}$

5.11

25

$-87$

5.11

$\begin{array}{llll}\mathrm{R} & 58 & -52 & 30\end{array}$

6.59

$-23$

5.11

Supramarginal gyrus

$\begin{array}{llll}\mathrm{L} & -50 & 26 & 23\end{array}$

5.57

58

51

26

7.63

$\begin{array}{llll}44 & -44 & 23 & 5.87\end{array}$

$\begin{array}{llll}-56 & -45 & 25 & 6.83\end{array}$

\section{Temporal}

Superior temporal gyrus/sulcus-TPJ

$\begin{array}{rrrrrrrrr}\mathrm{R} & 56 & -52 & 16 & 7.53 & 55 & -49 & 15 & 9.41 \\ \mathrm{~L} & -44 & -30 & 0 & 6.01 & -50 & -57 & 16 & 6.62 \\ \mathrm{R} & 49 & -40 & -3 & 6.03 & 49 & -40 & -3 & 5.98 \\ & 35 & -64 & 15 & 7.66 & 35 & -62 & 12 & 7.51 \\ \mathrm{~L} & -41 & -51 & 4 & 7.85 & -41 & -54 & 5 & 7.03\end{array}$

\section{Occipital}

Middle occipital gyrus

$\begin{array}{rrrrlrrrr}\mathrm{R} & 25 & -76 & 0 & 9.39 & 25 & -75 & 3 & 8.43 \\ \mathrm{~L} & -32 & -69 & 2 & 7.3 & -31 & -70 & 5 & 6.73\end{array}$


Table 3. (continued)

\begin{tabular}{|c|c|c|c|c|c|c|c|c|c|}
\hline \multirow[b]{2}{*}{ Anatomical Structure } & \multirow[b]{2}{*}{$H$} & \multicolumn{4}{|c|}{$S O A=100$ msec Versus Base } & \multicolumn{4}{|c|}{$S O A=500$ msec Versus Base } \\
\hline & & $x$ & $y$ & $z$ & Z Score & $x$ & $y$ & $z$ & Z Score \\
\hline \multicolumn{10}{|l|}{ Occipital } \\
\hline Fusiform gyrus & $\begin{array}{l}\mathrm{R} \\
\mathrm{L}\end{array}$ & $\begin{array}{r}37 \\
-37 \\
-47 \\
-29\end{array}$ & $\begin{array}{l}-69 \\
-43 \\
-52 \\
-80\end{array}$ & $\begin{array}{r}-9 \\
-12 \\
-13 \\
-4\end{array}$ & $\begin{array}{r}11.1 \\
6.63 \\
7.68 \\
8.97\end{array}$ & $\begin{array}{r}37 \\
-38 \\
-47 \\
-29\end{array}$ & $\begin{array}{l}-69 \\
-43 \\
-51 \\
-80\end{array}$ & $\begin{array}{r}-9 \\
-12 \\
-13 \\
4\end{array}$ & $\begin{array}{l}9.91 \\
6.79 \\
5.28 \\
6.87\end{array}$ \\
\hline Lingual gyrus & $\begin{array}{l}\mathrm{R} \\
\mathrm{L}\end{array}$ & $\begin{array}{r}11 \\
-17\end{array}$ & $\begin{array}{l}-84 \\
-83\end{array}$ & $\begin{array}{r}-3 \\
3\end{array}$ & $\begin{array}{l}13.5 \\
13.2\end{array}$ & $\begin{array}{r}10 \\
-17\end{array}$ & $\begin{array}{l}-84 \\
-83\end{array}$ & $\begin{array}{l}-3 \\
-3\end{array}$ & $\begin{array}{l}11.8 \\
10.9\end{array}$ \\
\hline \multicolumn{10}{|l|}{ Other } \\
\hline Thalamus/pulvinar & $\mathrm{L}$ & -7 & -25 & 13 & 8.46 & -10 & -17 & 8 & 8.49 \\
\hline Lentiform nucleus/putamen & $\mathrm{L}$ & -32 & -9 & -1 & 5.16 & -31 & -10 & -2 & 5.62 \\
\hline Lateral geniculate body & $\mathrm{L}$ & -20 & -18 & 2 & 7.63 & -23 & -25 & -1 & 5.74 \\
\hline Caudate tail & $\mathrm{R}$ & 34 & -20 & -8 & 5.89 & 34 & -23 & -5 & 5.93 \\
\hline \multirow[t]{2}{*}{ Cerebellum } & $\mathrm{R}$ & 19 & -51 & -10 & 8.75 & 19 & -48 & -13 & 9.35 \\
\hline & $\mathrm{L}$ & $\begin{array}{r}43 \\
22 \\
-23\end{array}$ & $\begin{array}{l}-63 \\
-43 \\
-48\end{array}$ & $\begin{array}{l}-24 \\
-29 \\
-25\end{array}$ & $\begin{array}{l}8.92 \\
7.6 \\
7.86 \\
-28\end{array}$ & $\begin{array}{r}43 \\
23 \\
-19 \\
-68\end{array}$ & $\begin{array}{l}-60 \\
-44 \\
-46 \\
-13\end{array}$ & $\begin{array}{l}-22 \\
-29 \\
-26 \\
6.25\end{array}$ & $\begin{array}{l}6.65 \\
5.88 \\
7.2\end{array}$ \\
\hline
\end{tabular}

For each anatomical location, the maximal group $Z$ score is given, along with its location in the coordinate space of Talairach and Tournoux (1988). $\mathrm{H}=$ hemisphere; $\mathrm{L}=$ left-hemisphere; $\mathrm{R}=$ right-hemisphere. (The activations listened in the table also contain local maxima within larger volumes. These were specified by searching the highest value in a radius of $5 \mathrm{~mm}$.)

activation below the chosen threshold of $Z>5$.

\section{Superior Colliculi}

The SC have been implied in the generation of IOR. We found no collicular activation in any of our contrasts. To investigate these negative findings in more detail, we plotted the amplitude changes for the left and right SC (Figure 5). They showed a substantial signal increase in all experimental conditions compared to the global average across the experiment, without significant differences between conditions. Accordingly, none of the two ANOVAs calculated for the left and right SC reached significance for interaction (all $p \mathrm{~s} \geq .421$ ), or main effects (SOA: all $p \mathrm{~s} \geq$ .707 ; validity: all $p s \geq .654)$.

\section{Task-Specific Activation Compared to Fixation}

Comparisons of valid and invalid trials against fixation trials for $\mathrm{SOA}=100 \mathrm{msec}$ and $\mathrm{SOA}=500 \mathrm{msec}$, respectively, revealed highly overlapping activations throughout a fronto-parietal network as described previously in numerous studies (see Table 2 for an overview of imaging studies, and Table 3 for the list of activations). The activation pattern consisted bilaterally of the pre-SEF, the FEF, and the junction of the precentral sulcus and inferior frontal sulcus, and in the left hemisphere the supplementary motor area and the motor cortex (opposite to the responding hand). Further bilateral activations were found in the superior frontal sulci, middle frontal gyri, insulae, anterior intraparietal sulci, extending into the superior parietal lobule (BA 7), posterior intraparietal sulci, at the junction to the transverse occipital sulcus, and bilateral temporo-parietal junction (TPJ) areas (supramarginal gyri and superior temporal gyri/sulci). Extensive bilateral ventral occipital cortex activation covered parts of the fusiform and lingual gyri. Subcortical activation was found in the left thalamus and bilaterally in the cerebellum.

\section{DISCUSSION}

\section{Areas Involved in Covert Reorienting}

A network of areas, mainly consisting of the LFPC, bilateral middle frontal gyri, and right cerebellum showed an interaction of cue validity and SOA (Figure 4a), which was, as expected from previous behavioral studies, also present in the RT data. ROI analyses of amplitude changes in the four major activated areas revealed that the nature of this interaction was the same as in the RT data: When detection latencies were short, namely, in valid trials at short SOA and invalid trials at long SOA, these areas were weakly activated; when latencies increased, in invalid trials at short and valid 
Table 4. Results of Repeated Measures ANOVAs with the Factors SOA (100 and $500 \mathrm{msec}$ ) and Validity (Valid, Invalid), and the Paired Sample $t$ tests for all Reported ROI

$A$

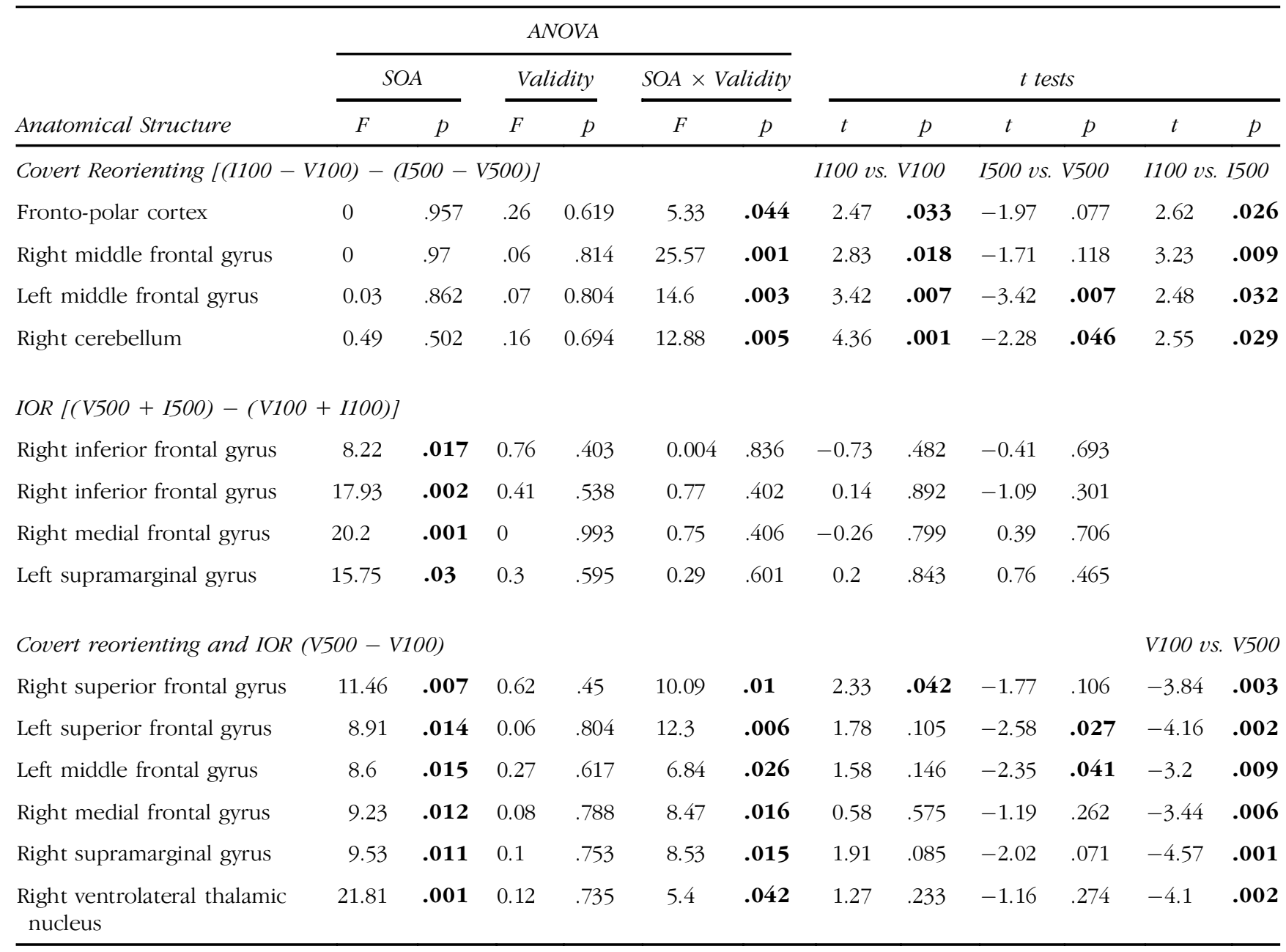

\begin{tabular}{|c|c|c|c|c|c|c|c|c|c|c|}
\hline \multicolumn{11}{|c|}{$B$} \\
\hline \multirow[b]{3}{*}{ Anatomical Structure } & \multicolumn{6}{|c|}{ ANOVA } & & & & \\
\hline & \multicolumn{2}{|c|}{$S O A$} & \multicolumn{2}{|c|}{ Validity } & \multicolumn{2}{|c|}{$S O A \times$ Validity } & \multicolumn{4}{|c|}{$t$ tests } \\
\hline & $F$ & $p$ & $F$ & $p$ & $F$ & $p$ & $t$ & $p$ & $t$ & $p$ \\
\hline Posterior medial frontal gyrus & 0.44 & .522 & 8.35 & .016 & 2.19 & .17 & 4.02 & .002 & 0.74 & .474 \\
\hline Anterior cingulate cortex & 3.01 & .113 & 6.05 & .034 & 4.69 & .056 & 3.03 & .013 & 1.02 & .334 \\
\hline Lingual gyrus & 0.59 & .46 & 6.69 & .027 & 8.61 & .015 & 3.52 & .006 & -0.55 & .592 \\
\hline
\end{tabular}

Significance criterion was set to $\alpha=.05$. [Areas revealed by several contrasts are only reported in one category: e.g., (V500 - V100). Abbreviations as in legend to Figure 4.]

trials at long SOA, their activation also increased. At the short SOA, invalid trials elicited significantly more activation than valid trials in all of these areas. However, signal variability was higher at the long SOA, leading to nonsignificant differences between valid and invalid trials in the LFPC and left anterior middle frontal gyrus. A significantly higher signal amplitude for correct detections of invalidly cued targets at short SOA was expected in brain areas that are involved in covert reorienting against attentional capture by an invalid location cue. 
Importantly, all of these areas were less activated when the target appeared at an uncued location at the long SOA, compared to the short SOA (Table 4a). This indicates that it is not target presentation at an uncued location as such that causes the activation, but that the activation reflects the brain's response to a target at an unattended location. A significant increase of activation in the contrast invalid/SOA $=100 \mathrm{msec}-\mathrm{valid} / \mathrm{SOA}=$ $100 \mathrm{msec}$ in the absence of a significant difference between valid and invalid trials at SOA $=500 \mathrm{msec}$ was observed in the "attention to action area" of the anterior cingulate cortex (Vogt, Finch, \& Olson, 1992). Corbetta, Miezin, Dobmeyer, Shulman, and Petersen (1991) reported a similar activation related to divided attention. Our activation may reflect the need to divide attention between the cue and target locations in invalid trials at $\mathrm{SOA}=100 \mathrm{msec}$, which is absent at $\mathrm{SOA}=500$ msec. This is probably due to the nearly simultaneous perception of the cue and the target at different locations, and therefore this process should be clearly distinguished from covert reorienting.

The LFPC activation is virtually identical to an activation that we found to accompany shifts of attention between visual dimensions (such as color and movement) in a visual search task (Pollmann, Weidner, et al., 2000). This experiment shared the stimulus-driven capture of attention with the present experiment. In the visual search experiment, LFPC showed increased activity when the target was defined in a new dimension, eliciting a stimulus-driven shift of attention from the old to the new dimension. Analogously, in the present study, we expected LFPC to show increased activation when subjects had to shift attention from the cued location to an uncued location, that is, with invalid cues at short SOA. This expectation was confirmed by the data. As discussed in the Introduction, it is not clear whether the prolonged detection times for validly cued targets at the long SOA represent the same process of attentional reorienting as in the short SOA, since it is not known whether IOR is caused by an attentional or motor bias. The significant cue $\times$ SOA interaction suggests that these brain areas are involved in the same attentional reorienting process in both SOA, while this attentional reorienting may be somewhat less pronounced at the long SOA, as indicated by the lack of significant activation differences in the left fronto-polar and middle frontal gyri.

Bilateral activations in the orbito-frontal cortex were reported to be associated with invalid cues in a positron emission tomography (PET) study of a combined spatial and temporal cueing paradigm (Nobre, Coull, Frith, \& Mesulam, 1999). However, these activations were nonoverlapping with our LFPC activation. This study differed from ours in that symbolic informative cues were used, inducing endogenous shifts of attention. Besides, due to technical limitation of the PET technique, Nobre et al. (1999) were not able to run an event-related analysis, instead varying the cueing validity over different blocks in their experiment. The orbito-frontal activation occurred in blocks with increased number of invalid trials (60\% vs. $0 \%$ invalid), so their orbito-frontal activation may have been due to changed expectation regarding cue validity. In fact, Nobre et al. interpreted their orbito-frontal cortex to be associated with such "breaches of expectation." This is unlikely to account for our LFPC activation, because we found this region to be activated although subjects knew that cueing validity was 50\%. In addition, the implemented randomization did not allow any valid predictions about the validity or SOA of an upcoming trial.

Recently, Koechlin, Corrado, Pietrini, and Grafman (2000) suggested the fronto-polar cortex (FPC) to be involved specifically in "branching," a term that they coined for carrying out a secondary task, while holding a primary task in working memory. As there is no dual task component in our task, our data indicate that "branching" is not a necessary precondition to obtain FPC activation. However, our data may support another aspect of the Koechlin et al. study. They suggested that lateral and anterior prefrontal cortices support exogenous and endogenous aspects of task control, respectively (Koechlin et al., 2000). We found a consistent activation of lateral LFPC with stimulus-driven attention shifts in the present study, as well as our previous study on stimulus-driven visual dimension change (Pollmann, Weidner, et al., 2000). In contrast, the fronto-median cortex was more strongly involved than lateral the FPC when visual dimension change was endogenously controlled (Weidner, Pollmann, Müller, \& von Cramon, in press).

A further activation related to covert reorienting was found in the right anterior middle frontal gyrus. Activations in approximately this region have been observed for attentional set shifting between different perceptual dimension in a Wisconsin Card Sorting task (Nagahama et al., 2001). In addition, the interaction contrast revealed activations in the left inferior FEF (Luna et al., 1998) and the right cerebellum, which are both known as parts of the fronto-parietal network supporting covert shifts of attention. Although the FEF are active during the generation of saccades, numerous studies have shown that they are also active during covert shifts of attention (e.g., Perry \& Zeki, 2000; Corbetta et al., 1998). Although we could not measure eye movements in the scanner, the low number of errors suggests that few if any eye movements were made (see Methods for details).

Activation in the right cerebellar hemisphere was found in an area previously reported to be involved in attention to specific form or color features (Allen, Buxton, Wong, \& Courchesne, 1997) and to elicit higher activation when covert spatial attention shifts were compared to eye movements (Corbetta et al., 1998). 
More cerebellar activations (although near threshold and of small spatial extent $\left[>21 \mathrm{~mm}^{3}\right]$ ) were found in the right medial cerebellum, and in the left lateral posterior cerebellum. Whereas the first fits the motor region, the two latter match the attentional region reported by Allen et al. (1997).

To summarize, the network of brain areas that we found to support covert reorienting consists of areas that all have previously been related to attentional processes, and specifically to attentional change. Our data do not allow to differentiate the specific contribution of these areas to covert reorienting. However, their activation profile indicates that they are conjointly active when subjects have to reorient from an attended location to process a target stimulus elsewhere in the visual field. That all of these areas also showed at least a trend for elevated activation levels for the detection of validly cued targets at the long SOA is not surprising, since increased attentional resources are needed for their detection in the presence of IOR. However, it should be noted that in all of these areas, the signal amplitude collapsed over valid and invalid trials did not increase with increasing SOA, which distinguishes the covert reorienting network from the IOR-related network of brain areas.

\section{Brain Areas Involved in the Generation of IOR}

As outlined in the Introduction, IOR increases over time and should lead to stronger activation with increasing SOA. Figure 1 illustrates the hypothetical time-courses of initial facilitation and IOR processes. When IOR begins after initial facilitation, it is obvious that it will only lead to activation at the long SOA. Alternatively, the onset of IOR may be concurrent with cue onset. In this case, the processes that generate IOR need to be initially weaker, but of longer duration than initial facilitation in order to elicit the delayed behavioral IOR effect. Thus, in the latter case we would also expect a stronger accumulated fMRI signal at the long SOA [cf. Dale \& Buckner (1997) for comparable signal accumulation effects].

A significant main effect of SOA (with increasing activation at the long SOA) was observed at the anterior border of the SEF (as described in a recent review by Grobras, Lobel, van de Moortele, LeBihan, \& Berthoz, 1999), as well as in the right posterior inferior frontal gyrus, extending into the inferior precentral sulcus. This area has previously been described as inferior FEF (Luna et al., 1998). Smaller activations were observed in the supramarginal gyri bilaterally, left inferior parietal lobule, in the ventrolateral nucleus of the thalamus, and in the left cerebellum.

The presence of the SEF and FEF among the areas that show an IOR-related activation pattern tends to support the oculomotor bias theory of IOR.

We did not find collicular involvement in the generation of IOR. As indicated by the signal amplitude changes (Figure 5), SC showed substantial signal increase in all experimental conditions, compared to baseline, but did not differ significantly between conditions. In a careful study of a patient with a right collicular lesion, Sapir et al. (1999) reported the absence of a Validity $\times$ SOA interaction when the cue was presented in the contralesional hemifield, while the interaction was significant in the ipsilesional field. Sapir et al. interpreted their data as direct evidence for collicular generation of IOR. While we found no specific confirmation of this claim, our data do not rule out collicular involvement in IOR. It may be that a specific collicular contribution to IOR was masked by a general collicular activation in covert shifts of attention, leading to a homogeneous signal increase over all experimental conditions.

In addition to the areas involved in oculomotor programming, we also found thalamic activation at the probable location of the ventrolateral nucleus. Since the ventrolateral nucleus is a central relay station of the sensorimotor system, it is tempting to assume that IOR inhibits motor responses beyond the oculomotor system. The only previous imaging study, to our knowledge, that investigated IOR (Rosen et al., 1999) reported the ventrolateral nucleus of the thalamus, although in the left hemisphere $(-13 /-18 / 9)$, as the only region selectively activated with IOR, as contrasted against resting conditions or endogenous cueing.

\section{Areas Involved in Covert Reorienting and IOR}

A third group of brain areas displayed both a significant main effect of SOA and a significant interaction of cue validity and SOA, indicating a contribution to both covert reorienting and IOR. These areas were the medial frontal gyrus (pre-SEF), posterior left superior frontal sulcus (pre-FEF), left middle frontal gyrus (close to the junction of the precentral sulcus and inferior frontal sulcus), right anterior superior frontal gyrus, right supramarginal gyrus (TPJ), and right ventrolateral nucleus of the thalamus.

The activation in the medial frontal gyrus is located anterior to the SEF (Grobras et al., 1999). Petit et al. (1996) proposed a subdivision of the SEF in a rostral and a caudal part, in analogy to the separation of the supplementary motor areas into preSMA and SMA, with the first suggested to play an important role for motor selection, and the latter for motor execution. Whereas the functional property of the caudal SEF is described as the performance and control of saccades, Petit et al. suggest the more rostral pre-SEF to be involved in the selection and control of prelearned saccadic eye movements, namely, of saccades guided by visuospatial data. The location of our activation coincides with the pre-SEF.

Activation of the posterior right superior frontal sulcus was found anterior to the junction with the superior 
precentral sulcus. Activation at this location was previously reported to show sustained activity during working memory delays (Courtney, Ungerleider, Keil, \& Haxby, 1996; Courtney, Petit, Maisog, Ungerleider, \& Haxby, 1998), which parallels the increase of activation with increasing SOA in our study. However, the delay activation in the studies by Courtney et al. developed over several seconds, whereas the SOA difference in our study was only $400 \mathrm{msec}$. Thus the significantly increased activation at the long SOA most probably reflects the strengthening of an active process from the short to the long SOA. A recent study of pro- and antisaccades may shed some light on the nature of this process (Connolly, Goodale, Desouza, Menon, \& Vilis, 2000). The area anterior to the junction of superior precentral and superior frontal sulci was termed preFEF by Connolly et al. (2000) (the border between FEF and pre-FEF was defined by the vertical plane through the anterior commissure). They found pre-FEF to be specifically activated by antisaccades, while antisaccades and prosaccades both elicited strong overlapping activation in FEF proper. Our activation in pre-FEF thus lends support to the hypothesis that IOR is due to inhibitory oculomotor processes.

Covert Reorienting/IOR-related activation was also found in the anterior right superior frontal gyrus. While less is known of the contribution of this area to visuospatial orienting, it has been reported that patients with lesions of the right superior frontal gyrus showed mild deficits in utilizing the information provided by advance cues (Koski, Paus, \& Petrides, 1998).

We also found increased activation in the posterior middle frontal gyrus, near the junction of the left inferior frontal and inferior precentral sulcus. Activation in this area was previously reported to follow manual response inhibition (Rubia et al., 2001; Konishi, Nakajiama, Uchida, Sekihara, \& Miyahita, 1998) and reversal of stimulusresponse association (Nagahama et al., 2001; Dove, Pollmann, Schubert, Wiggins, \& Cramon, 2000). However, this area may also be involved in oculomotor function. In a patient with a lesion of the right inferior frontal gyrus and ventral precentral gyrus, which encroached on the ventral aspect of the middle frontal gyrus, Walker, Husain, Hodgson, Harrison, and Kennard (1998) observed a failure to suppress reflexive saccades to peripheral stimuli in an antisaccade task. Thus, the posterior ventral frontal cortex seems to support inhibitory motor function both for manual and oculomotor responses. It was found activated when subjects inhibited a manual response, and inhibition of oculomotor responses was lacking when this area was lesioned.

An area that has been discussed in relation to target detection processes is the right temporo-parietal junction area. When lesioned, patients' detection of contralesional targets suffered in the presence of ipsilesional cues (Friedrich, Egly, Rafal, \& Beck, 1998). fMRI activation in this area was found to reflect target- related rather than cue-related processing (Corbetta, Kincade, Ollinger, McAvoy, \& Shulman, 2000). Both supramarginal gyri showed a significant SOA main effect, while only the right supramarginal gyrus, at a location virtually identical to one focus in the right inferior parietal lobule reported by Corbetta et al. (2000), showed a significant interaction of Cue validity $\times$ SOA. This suggests that the supramarginal gyri are both involved in the generation of IOR, whereas only the right is additionally involved in covert reorienting. This is consistent with the interpretation by Corbetta et al. that the right TPJ area may provide a spatial reorienting or nonspatial alerting signal.

\section{Inhibition of Return-Attentional or Motor Bias?}

Among the areas that showed a "pure" increase of activation over time were the right supplementary and inferior FEFs, two areas primarily involved in the planning and control of saccades. Interestingly, whereas pure IOR-related activation was observed in the SEF and FEF, an additional role in covert reorienting was found in areas anterior to the SEF and FEF. An involvement of pre-SEF and pre-FEF in covert reorienting fits well with the report that these areas also support antisaccades (Connolly et al., 2000). Thus, it seems that a distinction can be made between SEF and FEF participation in the generation of IOR, and pre-SEF and pre-FEF involvement when the subject has to reorient, either against stimulus-driven attentional capture or IOR.

Clinical data and functional imaging imply that the temporo-parietal junction area, specifically in the right hemisphere, is important for target detection at unattended locations (Corbetta et al., 2000; Friedrich et al., 1998). Our data confirm a role of the right supramarginal gyrus for covert reorienting, as well as bilateral supramarginal gyrus involvement in IOR. It is tempting to speculate that the right supramarginal gyrus may send target detection signals to the pre-SEF or preFEF, initiating reorienting, a topic that needs further investigation.

The data support the view that emerged from behavioral studies of IOR, in that oculomotor processes are involved in the generation of IOR, but that attentional factors are also intimately linked to IOR.

\section{Conclusion}

Three sets of brain areas were found, the first supporting covert reorienting, the second supporting IOR, while the third set supported both. Pure covert reorientingassociated activation was found primarily in the prefrontal cortex, while IOR was supported by a set of premotor (specifically oculomotor) areas, as well as the supramarginal gyri. Joint activation by covert reorienting and IOR was found in the pre-SEF and pre-FEF, which may link the attentional and oculomotor systems. 


\section{METHODS}

\section{Subjects}

Twenty subjects (10 women) participated in the fMRI experiment, each having given prior informed consent according to the Max-Planck-Institute guidelines. The study was approved by the local ethics review board at the University of Leipzig. All subjects were right handed, assessed by the Edinburgh Inventory (Oldfield, 1971). Subject age varied between 20- 29 years of age, with a mean age of 23 years. All subjects had normal or corrected to normal vision.

\section{Experimental Design}

We used a modified spatial cueing paradigm for covert exogenous orienting of attention (Posner, 1980; Posner \& Cohen, 1984) with premarked target locations. All cues were uninformative to the location of the target, that is, giving a valid prediction for the location of the target in 50\% of all cases a target was presented. In onethird of all trials no target was given (no-go condition), so the probability of a target appearing was 66\%.

For stimulus presentation we used an LCD projector with a back projection screen positioned in the rear-end bore of the magnet. The subject viewed the display wearing mirror-glasses, which were equipped with corrective lenses if necessary. During all trials the two possible positions of the target were premarked with dark-gray boxes (size $1.5^{\circ} \times 1.5^{\circ}$ visual angle, $22.2 \mathrm{~cd} / \mathrm{m}^{2}$ luminance), centered at $7.5^{\circ}$ eccentricity at the horizontal meridian. In the center of the screen a fixation-cross (extension of $0.5^{\circ}, 22.2 \mathrm{~cd} / \mathrm{m}^{2}$ ) was presented throughout the whole experiment. The cue stimuli were realized by the brightening of one of the peripheral boxes (263 $\mathrm{cd} / \mathrm{m}^{2}$ ) for $80 \mathrm{msec}$. After a variable delay (SOA of 100 , 200 , and $500 \mathrm{msec}$ ), a little dark-gray dot (radius $0.5^{\circ}$, $45.14 \mathrm{~cd} / \mathrm{m}^{2}$ ) appeared in the middle of one of the boxes for $80 \mathrm{msec}$.

Since direct control of eye-movements was not possible, we adjusted the luminance difference of targets compared to background $\left(2.88 \mathrm{~cd} / \mathrm{m}^{2}\right)$ to the effect that it was only feasible to detect the appearance of the target at both possible locations when the center fixation cross was fixated. In a pilot experiment, we found that it was much more difficult (if not impossible) to detect a target appearing at a peripheral position when fixating the contralateral position.

The participants were instructed to make a speeded button-press response with their right index finger to the appearance of the target. Subjects were instructed that no target appeared in some trials, and that they must not press a button in this case (no-go condition).

Each trial lasted $3 \mathrm{sec}$. Depending on the SOA, the interstimulus interval varied between 2420, 2720, and $2820 \mathrm{msec}$. Figure 2 gives an outline of the trial design.
Trial order was pseudorandomized to control the probability of transitions from one trial to the next (controlled for cue position, target position, SOA, valid trials, invalid trials, no-go trials, combinations of trial types and SOA, combinations of trial type, SOA, and position of the target). In previous studies, we have shown that the differential response to items presented in isolation, or embedded in a rapid stream of baseline items, did not change, provided that the time interval between repetitions of the same condition is not too short (Pollmann, Dove, von Cramon, \& Wiggins, 2000). With equal spacing, the minimum interval is about 6 sec (Pollmann, Wiggins, Norris, von Cramon, \& Schubert, 1998). In the present experiment, the mean interval between repetitions of the same condition was $27 \mathrm{sec}$. The number of trials was counterbalanced across conditions.

Stimulus onset was varied in relation to the timing of image acquisition. Due to the difference in trial length of $3 \mathrm{sec}$ and TR of $2 \mathrm{sec}$, the stimulus was presented either at the beginning of image acquisition or $1 \mathrm{sec}$ later. With this procedure the effective sampling rate is doubled and offers a higher temporal resolution for analysis (Miezin, Macotta, Ollinger, Petersen, \& Buckner, 2000; Josephs, Turner, \& Friston, 1997).

Before the beginning of each experiment, the participants received a training block of 54 trials in the scanner. An experiment consisted of five blocks of 54 trials. Before, after, and between blocks, a fixation cross was presented for $28 \mathrm{sec}$ followed by a brightening of the fixation cross for $2 \mathrm{sec}$ to indicate the start of the next block. In total, 30 repetitions per cueing condition and 90 repetitions of the no-go condition were obtained. The experiment lasted $16.5 \mathrm{~min}$.

A scanning session consisted of two scans, the first scan contained the above-described experiment. The second scan included a variation of the experiment that we will report separately.

\section{MRI Scanning Procedure}

Functional images were collected at $3 \mathrm{~T}$ by a Bruker 30/100 Medspec system (Bruker Medizintechnik, Ettlingen, Germany). A gradient-echo EPI sequence was used with a $\mathrm{TE}=30 \mathrm{msec}$, a flip angle of $90^{\circ}$, a TR $=2000$ msec, and an acquisition bandwidth of $100 \mathrm{kHz}$. The matrix acquired was $64 \times 64$ with a FOV of $19.2 \mathrm{~cm}$, resulting in an in-plane resolution of $3 \times 3 \mathrm{~mm}$. The slice thickness was $5 \mathrm{~mm}$ with an interslice gap of $2 \mathrm{~mm}$. Sixteen axial slices were acquired, oriented parallel to the AC- PC plane.

\section{fMRI Data Analysis}

Analysis of fMRI data was performed using the LIPSIA software package (Lohmann et al., 2001). The data were corrected for 2-D movement following the algorithm of 
Friston, Williams, Howard, Frackowiak, and Turner (1996) and then individually checked for remaining movement artifacts. Then, a correction for slice acquisition order using sinc interpolation was performed. The last step of preprocessing was the removal of low frequency baseline drifts with a temporal high-pass filter with a cutoff of $1 / 54 \mathrm{~Hz}$ (between-condition comparisons), respectively, $1 / 140 \mathrm{~Hz}$ (baseline comparisons), using a discrete Fourier transform. The high-pass filter cutoffs were calculated based on the temporal distribution of conditions. [Trials of the same condition had a mean spacing of $27 \mathrm{sec}$ within the experiment (66 sec for regarded baseline events), therefore oscillating with a frequency of $1 / 54 \mathrm{~Hz}$, respectively, $1 / 132 \mathrm{~Hz}$. The corresponding cutoff was set to the length of a full oscillation.]

The data were spatially smoothed with a Gaussian kernel with FWHM $=5.7 \mathrm{~mm}$. All functional datasets were individually registered into 3-D space using the subjects' individual high resolution anatomical images: The 2-D anatomical slices, geometrically aligned with the functional slices, were used to compute a transformation matrix, containing rotational and translational parameters that register the anatomical slices with the 3-D reference T1 dataset. Geometrical distortions of the EPI-T1 images were corrected using additional EPI-T1 refinement on the transformation matrices. Third, these transformation matrices were normalized to the standard Talairach brain size (Talairach \& Tournoux, 1988) by linear scaling, and then finally applied to the individual functional data.

The statistical evaluation was realized using the General Linear Model (Friston et al., 1995) for serially autocorrelated observations. For each individual subject statistical parametric maps (SPM) were generated. The design matrix for event-related analysis was created using a model of the hemodynamic response and its temporal derivative, which allows testing for differences in the amplitude of the BOLD response and its temporal onset. Even though we did not test for the latter, this model provides a better fit of the BOLD response, not depending on the fixed delay after stimulus onset. The model equation was convolved with a Gaussian kernel with a dispersion of $2.5 \mathrm{sec}$ FWHM. The increased temporal autocorrelation caused by filtering was corrected by an adjustment of the degrees of freedom. The contrast between the different conditions were calculated using $t$ statistics, afterwards $t$ values were transformed to $Z$ scores.

Group activations were calculated by one-sample $t$ tests at corresponding voxels of the individual $\operatorname{SPM}\{z\}$ across subjects (Bosch, 2000). Significance criterion was $\alpha=.0005$ ( $\alpha=.00003$ for baseline comparisons), uncorrected for multiple comparisons. All presented SPM $\{z\}$ maps were mapped onto a mean brain, averaged out of the normalized individual high-resolution anatomical datasets of the 11 subjects.
All events in the design file were logged to cue-onset. Analogous to the behavioral data analysis, again all error-trials, outliers, and trials immediately following resting baselines were excluded from the analysis. The baseline periods of $28 \mathrm{sec}$ were treated as follows: The first $10 \mathrm{sec}$ were rejected to eliminate the overlap from BOLD responses of the preceding block. The following $18 \mathrm{sec}$ were divided into six single events, according to a trial length of $3 \mathrm{sec}$. In total 30 baseline events were acquired.

The percent signal change of the BOLD response (relative to the grand mean in the specific region throughout the whole experiment) in regions specified by the calculated contrasts were extracted as follows: Starting with the center of activation in the group $\operatorname{SPM}\{z\}$, we performed a search for the most activated voxel in a radius of $6 \mathrm{~mm}$ for each subject individually. For each condition a peak search over the time-course was performed between 1 and 8 sec after cue onset, and subsequently these peaks were averaged across subjects. The confidence intervals $(\alpha=.05$, two-sided) for withinsubject designs are calculated following the method described by Loftus and Masson (1994) (the confidence intervals were calculated individually for condition means, and are equivalent to one-sample $t$ tests).

A slightly different method was chosen to obtain the percent signal change in the superior colliculus. Because this structure is too small to vindicate a search within 6 $\mathrm{mm}$ based on mean Talairach coordinates, we looked for the superior colliculus in the subjects' individual high resolution anatomical datasets, and performed a search for the most activated voxel only within a radius of 2 $\mathrm{mm}$. These voxels entered the analysis as described above.

\section{Acknowledgments}

We wish to thank two anonymous reviewers for their thoughtful comments on an earlier version of this manuscript.

Reprint requests should be sent to Jöran Lepsien, Max-PlanckInstitute of Cognitive Neuroscience, Stephanstrasse 1a, D04103 Leipzig, Germany, or via e-mail: lepsien@cns.mpg.de.

The data reported in this experiment have been deposited in the fMRI Data Center (http://www.fmridc.org). The accession number is 2-2001-111WF.

\section{REFERENCES}

Allen, G., Buxton, R. B., Wong, E. C., \& Courchesne, E. (1997). Attentional activation of the cerebellum independent of motor involvement. Science, 275, 1940- 1943.

Bosch, V. (2000). Statistical analysis of multi-subject fMRI data: Assessment of focal activations. Journal of Magnetic Resonance Imaging, 11, 61- 64.

Brefczynski, J. A., \& DeYoe, E. A. (1999). A physiological correlate of the "spotlight" of visual attention. Nature Neuroscience, 2, 370-374.

Collie, A., Maruff, P., Yucel, M., Danckert, J., \& Currie, J. (2000). Spatiotemporal distribution of facilitation and inhibition of 
return arising from the reflexive orienting of covert attention. Journal of Experimental Psychology, Human Perception and Performance, 26, 1733- 1745.

Connolly, J. D., Goodale, M. A., DeSouzza, J. F. X., Menon, R. S., \& Vilis, T. (2000). A comparison of frontoparietal fMRI activation during anti-saccades and anti-pointing. Journal of Neurophysiology, 84, 1645- 1655.

Corbetta, M., Akbudak, E., Conturo, T. E., Snyder, A. Z., Ollinger, J. M., Drury, H. A., Lineweber, M. R., Petersen, S. E., Raichle, M. E., van Essen, D. C., \& Shulman, G. L. (1998). A common network of functional areas for attention and eye movements. Neuron, 21, 761- 773.

Corbetta, M., Kincade, J. M., Ollinger, J. M., McAvoy, M. P., \& Shulman, G. L. (2000). Voluntary orienting is dissociated from target detection in human posterior parietal cortex. Nature Neuroscience, 3, 292- 297.

Corbetta, M., Miezin, F. M., Dobmeyer, S., Shulman, G. L., \& Petersen, S. E. (1991). Selective and divided attention during visual discriminations of shape, color, and speed: Functional anatomy by positron emission tomography. Journal of Neuroscience, 11, 2383- 2402.

Corbetta, M., Miezin, F. M., Shulman, G. L., \& Petersen, S. E. (1993). A PET study of visuospatial attention. Journal of Neuroscience, 13, 1202- 1226.

Coull, J. T., \& Nobre, A. C. (1998). Where and when to pay attention: The neural systems for directing attention to spatial locations and to time intervals as revealed by both PET and fMRI. Journal of Neuroscience, 18, 7426- 7435.

Courtney, S. M., Petit, L., Maisog, J. M., Ungerleider, L. G., \& Haxby, J. V. (1998). An area specialized for spatial working memory in human frontal cortex. Science, 279, 1347- 1351.

Courtney, S. M., Ungerleider, L. G., Keil, K., \& Haxby, J. V. (1996). Object and spatial visual working memory activate separate neural systems in human cortex. Cerebral Cortex, 6, 39- 49 .

Dale, A., \& Buckner, R. (1997). Selective averaging of rapidly presented individual trials using fMRI. Human Brain Mapping, 5, 329-340.

Dove, A., Pollmann, S., Schubert, T., Wiggins, C. J., \& Cramon, D. Y. (2000). Prefrontal cortex activation in task switching: An event-related fMRI study. Cognitive Brain Research, 9, 103- 109.

Friedrich, F. J., Egly, R., Rafal, R. D., \& Beck, D. (1998). Spatial attention deficits in humans: A comparison of superior parietal and temporal- parietal junction lesion. Neuropsychology, 12, 193- 207.

Friston, K. J., Holmes, A. P., Worsley, K. J., Poline, J. B., Frith, C. D., \& Frackowiak, R. S. J. (1995). Statistical parametric maps in functional imaging: A general linear approach. $\mathrm{Hu}$ man Brain Mapping, 2, 189- 210.

Friston, K. J., Williams, S., Howard, R., Frackowiak, R. S. J., \& Turner, R. (1996). Movement-related effects in fMRI timeseries. Magnetic Resonance Imaging, 35, 346- 355.

Gitelman, D. I., Nobre, A. C., Parrish, T. B. LaBar, K. S. Kim, Y.-H., Meyer, J. R., \& Mesulam, M. M. (1999). A large-scale distributed network for covert spatial attention. Brain, 122, 1093- 1106.

Grobras, M.-H., Lobel, E., van de Moortele, P.-F., LeBihan, D., \& Berthoz, A. (1999). An anatomical landmark for the supplementary eye fields in human revealed with functional magnetic resonance imaging. Cerebral Cortex, 9, 705- 711.

Hopfinger, J. B., Buoncore, M. H., \& Mangun, G. R. (2000). The neural mechanisms of top-down attentional control. Nature Neuroscience, 3, 284- 291.

Josephs, O., Turner, R., \& Friston, K. (1997). Event-related fMRI. Human Brain Mapping, 5, 243- 248.
Kim, Y., Gitelman, D. R., Nobre, A. C., Parrish, T. B., LaBar, K. S., \& Mesulam, M. M. (1999). The large-scale neural network for spatial attention displays multifunctional overlap but differential asymmetry. Neuroimage, 9, 269- 277.

Kingstone, A., \& Pratt, J. (1999). Inhibition of return is composed of attentional and oculomotor processes. Perception and Psychophysics, 61, 1046- 1054.

Klein, R. M. (2000). Inhibition of return. Trends in Cognitive Neuroscience, 4, 138- 147.

Koechlin, E., Corrado, G., Pietrini, P., \& Grafman, J. (2000). Dissociating the role of the medial and lateral anterior prefrontal cortex in human planning. Proceedings of the $\mathrm{Na}$ tional Academy of Sciences, U.S.A., 97, 7651- 7656.

Konishi, S., Nakajima, K., Uchida, I., Sekihara, K., \& Miyashita, Y. (1998). No-go dominant brain activity in human inferior prefrontal cortex revealed by functional magnetic resonance imaging. European Journal of Neuroscience, 10, 1209- 1213.

Koski, L. M., Paus, T., \& Petrides, M. (1998). Directed attention after unilateral frontal excisions in humans. Neuropsychologia, 36, 1363- 1371.

Loftus, G. R., \& Masson, M. E. J. (1994). Using confidence intervals in within-subject designs. Psychonomic Bulletin and Review, 1, 476- 490.

Lohmann, G., Müller, K., Bosch, V., Mentzel, H., Hessler, S., Chen, L., \& von Cramon, D. Y. (2001). Lipsia-A new software system for the evaluation of functional magnetic resonance images of the human brain. Computerized Medical Imaging and Graphics, 25, 449- 457.

Luna, B., Thulborn, K. R., Strojwas, M. H., McCurtain, B. J., Berman, R. A., Genovese, C. R., \& Sweeney, J. A. (1998). Dorsal cortical regions subserving visually guided saccades in humans: An fMRI study. Cerebral Cortex, 8, 40- 47.

Miezin, F. M., Maccotta, L., Ollinger, J. M., Petersen, S. E., \& Buckner, R. L. (2000). Characterizing the hemodynamic response: Effects of presentation rate, sampling procedure, and the possibility of ordering brain activity based on relative timing. Neuroimage, 11, 735- 759.

Nagahama, Y., Tomohisa, O., Katsumi, Y., Hayashi, T., Yamauchi, H., Oyanagi, C., Konishi, J., Fukuyama, H., \& Shibasaki, H. (2001). Dissociable mechanisms of attentional control within the human prefrontal cortex. Cerebral Cortex, 11, 85- 92.

Nobre, A. C., Coull, J. T., Frith, C. D., \& Mesulam, M. M. (1999). Orbitofrontal cortex is activated during breaches of expectation in task of visual attention. Nature Neuroscience, 2, 11- 12.

Nobre, A. C., Gitelman, D. R., Dias, E. C., \& Mesulam, M. M. (2000). Covert visual spatial orienting and saccades: Overlapping neural systems. Neuroimage, 11, 210- 216.

Nobre, A. C., Sebestyen, G. N., Gitelman, D. R., Mesulam, M. M. Frackowiak, R. S. J., \& Frith, C. D. (1997). Functional localization of the system for visuospatial attention using positron emission tomography. Brain, 120, 515- 533.

Oldfield, R. C. (1971). The assessment and analysis of handedness: The Edinburgh Inventory. Neuropsychologia, 9, 97- 113 .

Paus, T. (1996). Location and function of the human frontal eye-fields: A selective review. Neuropsychologia, 34, 475- 483.

Perry, R. J., \& Zeki, S. (2000). The neurology of saccades and covert shifts in spatial attention: An event-related fMRI study. Brain, 123, 2273- 2288.

Petit, L., Orssaud, C., Tzourio, N., Crivello, F. Berthoz, A., \& Mazoaer, B. (1996). Functional anatomy of a prelearned sequence of horizontal saccades in humans. Journal of Neuroscience, 16, 3714- 3726.

Pollmann, S., Dove, A., von Cramon, D. Y., \& Wiggins, 
C. J. (2000). Event-related fMRI: Comparison of conditions with varying BOLD-overlap. Human Brain Mapping, 9, 26-37.

Pollmann, S., Weidner, R., Müller, H. J., \& von Cramon, D. Y. (2000). A fronto-posterior network involved in visual dimension changes. Journal of Cognitive Neuroscience, 12, 480- 494.

Pollmann, S., Wiggins, C. J., Norris, D. G., von Cramon, D. Y., \& Schubert, T. (1998). Use of short intertrial intervals in singletrial experiments: A 3T fMRI-study. Neuroimage, 8, 327- 339.

Posner, M. I. (1980). Orienting of attention. Quarterly Journal of Experimental Psychology, 32, 3- 25.

Posner, M. I., \& Cohen, Y. (1984). Components of visual orienting. In H. Bouma \& D. Bouwhhuis (Eds.), Attention and Performance (pp. 531- 556). Hillsdale, NJ: Erlbaum.

Posner, M. I., Rafal, R. D., Choate, L. S., \& Vaughan, J. (1985). Inhibition of return: Neural basis and function. Cognitive Neuropsychology, 2, 211- 228.

Reuter-Lorentz, P. A., Jha, A. P., \& Rosenquist, J. N. (1996). What is inhibited in inhibition of return? Journal of Experimental Psychology, Human Perception and Performance, 22, 376- 378.

Rosen, A. C., Rao, S. M., Caffarra, P., Scaglioni, A., Bobholz, J. A., Woodley, S. J., Hammeke, T. A., Cunnigham, J. M., Prieto, T. E., \& Binder, J. R. (1999). Neural basis of endogenous and exogenous spatial orienting: A functional MRI study. Journal of Cognitive Neuroscience, 11, 135- 152.

Rubia, K., Russell, T., Overmeyer, S., Brammer, M. J., Bullmore, E. T., Sharma, T., Simmons, A., Williams, S. C. R., Giampietro, V., Andrew, C. M., \& Taylor, E. (2001). Mapping motor inhibition: Conjunctive brain activations across different versions of go/no-go and stop tasks. Neuroimage, 13, 250- 261.
Sapir, A., Soroker, N., Berger, A., \& Henik, A. (1999). Inhibition of return in spatial attention: Direct evidence for collicular generation. Nature Neuroscience, 2, 1053- 1054.

Talairach, J., \& Tournoux, P. (1988). Co-planar stereotactic atlas of the buman brain. Stuttgart: Thieme.

Tassinari, G., Aglioti, S., Chelazzi, L., Marzi, C. A., \& Berlucchi, G. (1987). Distribution in the visual field of the costs of voluntarily allocated attention and the inhibitory after-effects of covert orienting. Neuropsychologia, 25, 55- 71.

Tassinari, G., Biscaldi, M., Marzi, C. A., \& Berlucchi, G. (1989). Ipsilateral inhibition and contralateral facilitation of simple reaction time to non-foveal visual targets from non-informative visual cues. Acta Psychologia, 70, 267- 291.

Taylor, T. L., \& Klein, R. M. (1998). On the causes and effects of inhibition of return. Psychonomic Bulletin and Review, 5, 625- 643 .

Taylor, T. L., \& Klein, R. M. (2000). Visual and motor effects in inhibition of return. Journal of Experimental Psychology, Human Perception and Performance, 26, 1639- 1656.

Tootell, R. B. H., Hadjikhani, N., Hall, E. K., Marret, S., Vanduffel, W., Vaughan, J. T., \& Dale, A. M. (1998). The retinotopy of visual spatial attention. Neuron, 21, 1409- 1422.

Vogt, B. A., Finch, D. M., \& Olson, C. R. (1992). Functional heterogeneity in cingulate cortex: The anterior executive and posterior evaluative regions. Cerebral Cortex, 2, 435- 443.

Walker, R., Husain, M., Hodgson, T. L., Harrison, J., \& Kennard, C. (1998). Saccadic eye movement and working memory deficits following damage in human prefrontal cortex. Neuropsychologia, 36, 1141- 1159.

Weidner, R., Pollmann, S., Müller, H. J., \& von Cramon, D. Y. (in press). Top down controlled visual dimension weighting: An event-related fMRI study. Cerebral Cortex. 